\title{
Out-of-school time STEM program: Students' attitudes toward and career interests in mathematics and science
}

\author{
Guan Kung Saw ${ }^{1}$, Brendan Swagerty ${ }^{2}$, Shon Brewington ${ }^{3}$, Chi-Ning Chang ${ }^{4}$, Ryan Culbertson ${ }^{5}$ \\ ${ }_{1,2,3}$ Department of Educational Psychology, University of Texas at San Antonio, USA \\ ${ }^{4}$ Department of Educational Psychology, Texas A\&M University, USA \\ ${ }^{5}$ Institute for P-20 Initiatives, University of Texas at San Antonio, USA
}

\begin{tabular}{|c|c|}
\hline Article Info & ABSTRACT \\
\hline Article history: & Internationally, out-of-school time (OST) science, technology, engineering, \\
\hline Received Mar 8, 2019 & and mathematics (STEM) programs abound. However, rigorous evidence of \\
\hline Revised Apr 25, 2019 & their impacts on student outcomes is scarce. This study evaluated the \\
\hline Accepted May 4, 2019 & motivational factors in math and science by analyzing survey and \\
\hline & $\begin{array}{l}\text { administrative data of } 1.017 \text { middle school students who participated in the } \\
\text { seven-week, STEM-focused Prefreshman Engineering Program (PREP) in }\end{array}$ \\
\hline Keywords: & San Antonio, Texas, from 2015 to 2017. Multiple regression results indicated \\
\hline Middle school students & that the PREP participation was positively associated with students' attitudes \\
\hline Multiple regression & toward math and interests in math-related careers, whereas the effects on \\
\hline STEM motivation & negligible. No evidence was found to suggest that the associations between \\
\hline STEM summer program & $\begin{array}{l}\text { PREP participation and student motivational factors in math and science } \\
\text { differed by gender, race/ethnicity, or socioeconomic status. }\end{array}$ \\
\hline
\end{tabular}

Copyright (C) 2019 Institute of Advanced Engineering and Science. All rights reserved.

\section{Corresponding Author:}

Guan Saw,

Department of Educational Psychology,

University of Texas at San Antonio,

501 W. Cesar E. Chavez Blvd. San Antonio, TX 78207, USA.

Email: guan.saw@utsa.edu.

\section{INTRODUCTION}

Enhancing science, technology, engineering, and mathematics (STEM) education and workforce has been a priority for many countries to compete in the global economy [1,2]. The interest in improving STEM learning and participation has led to the creation and growth of various in- and out-of-school programs aimed at increasing the number of young students pursuing a college degree and ultimately a career in STEM fields. In the United States, for example, establishing more inclusive STEM high schools represents one rapidly expanding in-school STEM reform program $[3,4]$. In the out-of-school contexts, many public and private organizations offer STEM outreach programs during school summer holidays (June to August) that are designed to stimulate or maintain an interest in STEM careers among students at the elementary, secondary, and postsecondary level. These STEM summer programs typically include STEM-focused learning activities such as math/science enrichment curriculum, STEM career seminars, and field trips to STEM professional settings [5-7].

Although out-of-school time (OST) STEM programs abound in the US and internationally, rigorous research on their effects on student outcomes is limited. The existing evidence is mixed at best. While several studies generally found positive effects on student cognitive and motivational outcomes [7-13], others failed to detect an effect of OST STEM program participation on desirable student STEM outcomes, such as STEM interest and college major [14-16]. The mixed findings of prior studies stemmed in part from research designs that relied on small sample sizes and imprecise outcome measures. There is clearly the need for more empirical 
studies on the impact of OST STEM programs with larger student samples and more valid and reliable measures.

\section{LITERATURE REVIEW}

OST STEM programs in the USA and across the globe typically seek to increase students' attitudes toward and career interests in STEM through various approaches. Most OST STEM programs develop a STEM-based curriculum to improve students' critical thinking skills and knowledge as well as their motivational factors in STEM. These curricula tend to include a series of teaching and learning activities such as advanced coursework, hands-on activities, and group projects [17-19]. For example, Niemann, Miller, and Davis [12] reported that the Summer Science Institute, offered by the University of Alabama at Birmingham, Alabama, was a three-year progression of summer programs designed to introduce high school students to increasingly more rigorous scientific concepts and research skills through laboratory-based advanced science coursework over the course of three summers (six-week, three-day per week course each summer). The study found that students who returned each year were rated as being more motivated in learning science compared with first-year attendees by mentors, and students overall developed a deep understanding of what it is like to be a scientist. Similarly, several other studies based in various states in the US and focusing on STEM learning $[9,17,20]$ concluded that their OST STEM programs' curriculum positively impacted students' attitudes toward and career interest in STEM.

In addition to rigorous coursework or enrichment learning activities, many OST STEM programs create opportunities for students to be exposed to real-world STEM professionals and settings, which are often unavailable during regular school hours [6]. These real-world STEM exposure activities include STEM career seminars featuring professionals from various STEM fields and STEM-related field trips such as visiting science museums, nature centers, and information technology companies. A growing body of research has reported that these opportunities of exposure to real-world STEM professionals and settings can boost students' attitudes toward and career interests in STEM [9, 21, 22]. For instance, Mohr-Schroeder and colleagues [22] demonstrated that middle school students who participated in a STEM summer program in Kentucky either developed an interest in STEM fields or their interest in STEM was heightened through touring and conducting hands-on learning activities in engineering laboratories and facilities, led by engineering experts. Elam, Donham, and Soloman [6] documented that middle and high school students who attended a two-week engineering summer program in Texas reported an increase in career interests in science and engineering, which could partially be explained by their positive experiences from interacting with professional scientists and engineers as well as visiting a food manufacturing plant and a construction site. Taken together, these studies offer evidence that exposing students to STEM professionals and environments can boost their attitudes toward and career interests in STEM.

Despite informative findings, previous studies are limited in terms of methodological issues. They were largely descriptive in nature, and their studied samples tended to be small (typically composed of no more than a few dozens of participants). Most studies used only single-item survey measures to assess the impact of STEM summer programs on student outcomes, which have low level of measurement reliability and validity. Moreover, student samples in prior studies were not sociodemographically diverse, and therefore, had limited generalizability and offered no estimates for different sociodemographic subgroups, which could be informative evidence for understanding the changes in STEM motivations among underrepresented groups [23, 24]. Improving on prior work, this study aimed to assess the associations between OST STEM program participation and students attitudes toward and career interests in STEM by analyzing multiple years of data from a STEM summer program based in San Antonio, Texas, USA, with a sizable and diverse student sample and a rich set of measures on students' attitudes toward and career interests in math and science.

\section{METHOD}

To investigate the relationships between OST STEM program participation and student motivational factors, this study employed multiple regression models with covariate adjustments to analyze multiple years of participant data from the Prefreshman Engineering Program (PREP) in San Antonio, Texas, USA. PREP is a seven-week STEM summer program offered to middle and high school students in grades six to eleven, over the course of four summers with different levels of STEM curriculum and learning activities. PREP was founded at the University of Texas at San Antonio (UTSA) in 1979 to prepare young students, especially women, underrepresented racial/ethnic minorities (URM, who were mostly Blacks, Hispanics, and Native Americans, as opposed to Whites and Asians), and low-socioeconomic status (SES) students, for success in advanced studies leading to careers in STEM. In the summer of 2018, there were 40 PREP sites across the state of Texas, New Mexico, Arizona, California, Utah, and North Dakota, enrolling over 4,000 students. This study 
focused only on the PREP sites in San Antonio, which surveyed STEM motivations of participants in every summer since 2015.

PREP pursues its' mission by providing students a rigorous STEM-based curriculum taught by college professors or certified teachers for seven weeks (four days per week; 140 instructional hours in total) during the summer, where students attend program activities Mondays through Thursdays and the average day is six to seven hours long plus homework. The rigorous curriculum consists of various hands-on activities, group projects, and STEM coursework that facilitates the growth of essential academic and cognitive skills needed for STEM success. In particular, PREP exposes middle and high school students to advanced courses, including logic and applications to mathematics, introduction to engineering, introduction to physics, statistics and probability, and introduction to computer science, to help prepare students for advancement in STEM. PREP also provides opportunities for students to engage with STEM professionals through STEM-related field trips and daily STEM career seminars. Over the course of the seven week program, students engage with different STEM professionals through roughly two dozen of career seminars and at least one STEM-related field trip to enhance their attitudes toward and career interests in STEM.

\subsection{Sample}

By utilizing three years of student data from PREP sites in San Antonio (2015 to 2017), rising $8^{\text {th }}$ graders $\left(7^{\text {th }}\right.$ graders in prior school year) who participated in PREP for the second time were identified as the "treatment group," whereas the "comparison group" consisted of rising $8^{\text {th }}$ graders who were first-time PREP participants. In other words, students in the treatment group attended one additional seven-week PREP program, compared with the comparison group. The analytic sample of this study includes a total of 1.017 rising $8^{\text {th }}$ graders, consisting of 641 treated and 376 comparison cases. Table 1 shows descriptive statistics on the demographic characteristics of study samples by treatment status. Chi-square $\left(x^{2}\right)$ test results indicate that there was no significant difference by gender between treated and comparison groups (56\% versus $52 \%$ ). However, the comparison group had disproportionately more underrepresented racial/ethnic minorities $(81 \%)$ and low-SES students (37\%), compared with the treatment group ( $76 \%$ and $31 \%$, respectively).

Table 1. Demographic characteristics of study sample ( $\mathrm{N}=1.017)$

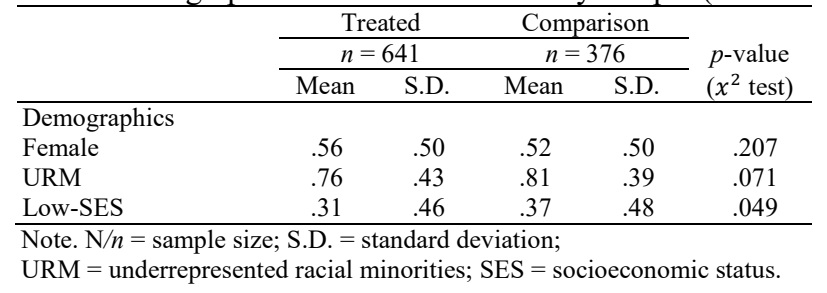

\subsection{Measures}

In this study, four measures on student STEM motivations are used as outcomes. The first two outcome measures are math attitudes and science attitudes, assessed by using the scales of student attitudes toward STEM, developed by Unfried and colleagues [25]. Both scales of the math and science attitudes consist of seven items with a five-point Likert scale ("strongly disagree" up to "strongly agree"). Two example items for measuring math attitudes are: "I am the type of student to do well in math" and "I can get good grades in math." Two example items for assessing science attitudes are: "I am sure of myself when I do science" and "I know I can do well in science" (see Table 2 for the complete set of items for both math and science attitudes). The third and fourth outcome measures are interest in math-related careers and interest in science-related careers, which were assessed by asking students to respond to the following two statements: "I would consider choosing a career that uses math" and "I would consider a career in science" (five-point Likert scale: "strongly disagree" up to "strongly agree"). These two items were coded into binary variables, indicating whether a student is interested in math- or science-related careers.

\subsection{Analytic strategy}

Confirmatory factor analysis (CFA) was applied to test the validity and to compute the standardized composite scores of math and science attitudes [26]. To evaluate the goodness-of-fit of CFA model, Hu and Bentler [27] recommended that a Root Mean Square Error of Approximation (RMSEA) at or below 0.06 indicates a good fit, whereas Comparative Fit Index (CFI) and Tucker-Lewis Index (TLI) greater than 0.95 are preferred. Reliability tests were conducted to calculate Cronbach's alpha coefficients for the two constructs of 
math and science attitudes [28]. To quantify the relationships of STEM summer program participation and students' attitudes toward and career interests in math and science, multiple regression models with covariate adjustments were used. For the dependent variables of interests in math/science-related careers that were dichotomous, regression models were estimated with a linear probability model [29]. To test the heterogeneous effects of PREP, a series of regression models were re-estimated by adding the interaction term between treatment status and sociodemographic characteristics, defined by gender, race/ethnicity, and SES. Robust standard errors were computed and used for statistical significance tests. All data was analyzed using STATA 14.2.

\section{RESULTS AND DISCUSSION}

\subsection{Results of confirmatory factor analyses for math and science attitudes}

Confirmatory factor analysis results showed an adequate fit of the model $\left(x^{2}(66)=175.3, p<.001\right.$; RMSEA $=0.040 ; \mathrm{CFI}=0.985 ; \mathrm{TFI}=0.980)$ for constructing two latent factors-math and science attitudesfrom 14 survey items, with the exception of a significant $x^{2}$ value due to the large sample size. As shown in Table 2, most of the factor loadings were large $(>.60)$ and all of them were statistically significant. The calculated Cronbach's alpha coefficients for math and science attitudes were both 0.88 , exceeding the 0.60 threshold. Taken together, these results suggest the two constructs of math and science attitudes possessed adequate reliability and validity, as indicated in the Unfried and colleagues [21].

Table 2. Results of confirmatory factor analysis and reliability test

\begin{tabular}{lcc}
\hline & Factor Loading & Alpha \\
\hline Math Attitudes & .88 \\
${ }^{a}$ Math has been my worst subject & .80 & .76 \\
${ }^{\text {a }}$ ath is hard for me & .79 & .77 \\
I am the type of student to do well in math & .66 \\
a can handle most subjects well, but I cannot do a good job with math & .67 \\
I am sure I could do advanced work in math & .84 & .88 \\
I can get good grades in math & & .66 \\
I am good at math & .81 \\
Science Attitudes & .80 & .84 \\
I am sure of myself when I do science & .66 \\
I expect to use science when I get out of school & .83 \\
Knowing science will help me earn a living & .70 \\
I will need science for my future work & \\
I know I can do well in science & \\
Science will be important to me in my life's work & \\
I am sure I could do advanced work in science &
\end{tabular}

Note. ${ }^{\text {a}}$ Reversed coded in factor analysis. Sample size is 1.017 students.

\subsection{STEM summer program participation and attitudes toward math and science}

Having constructed the two outcome measures of student motivational factors-math and science attitudes, we examined their relationships with the STEM summer program participation. Table 3 displays results from estimating a series of multiple regression models that predict math and science attitudes with PREP participation, controlling for sociodemographic characteristics. It appeared that participating in a STEM summer program is positively associated with students' attitudes toward math $(\beta=0.112, p<0.01)$ but has no effect on science attitudes. The estimates on a couple of socio-demographic characteristics were in the expected direction. For example, women and URMs had a significantly lower level of attitudes toward math. Furthermore, the interaction effects models (Models 2 to 4) suggested that the relationships among STEM summer program participation and math and science attitudes were not varied across sociodemographic groups, defined by gender, race/ethnicity, and SES. 
Table 3. Results of multiple linear regression models $(\mathrm{N}=1.017)$

\begin{tabular}{|c|c|c|c|c|c|c|c|c|}
\hline & \multicolumn{2}{|c|}{ Model 1} & \multicolumn{2}{|c|}{ Model 2} & \multicolumn{2}{|c|}{ Model 3} & \multicolumn{2}{|c|}{ Model 4} \\
\hline & $\beta$ & $R S E$ & $\beta$ & $R S E$ & $\beta$ & $R S E$ & $\beta$ & $R S E$ \\
\hline \multicolumn{9}{|l|}{ Panel 1: Math Attitudes } \\
\hline STEMSP & $.112^{* *}$ & $(.038)$ & .074 & $(.052)$ & $.198^{*}$ & $(.086)$ & $.131^{*}$ & $(.051)$ \\
\hline Female & $-.157 * * *$ & $(.036)$ & $-.201 * * *$ & $(.058)$ & $-.156 * * *$ & $(.036)$ & $-.159 * * *$ & $(.036)$ \\
\hline URM & $-.124 * *$ & $(.045)$ & $-.124 * *$ & $(.045)$ & -.052 & $(.079)$ & $-.124 * *$ & $(.045)$ \\
\hline Low-SES & .027 & $(.042)$ & .025 & $(.042)$ & .028 & $(.042)$ & .027 & $(.066)$ \\
\hline STEMSP $\times$ Female & & & .071 & $(.074)$ & & & & \\
\hline STEMSP $\times$ URM & & & & & -.109 & $(.095)$ & & \\
\hline STEMSP $\times$ Low-SES & & & & & & & .002 & $(.085)$ \\
\hline Intercept & .079 & $(.055)$ & .102 & $(.059)$ & .021 & $(.079)$ & .069 & $(.062)$ \\
\hline$R^{2}$ & \multicolumn{2}{|c|}{.038} & \multicolumn{2}{|c|}{.038} & \multicolumn{2}{|c|}{.039} & \multicolumn{2}{|c|}{.039} \\
\hline \multicolumn{9}{|l|}{ Panel 2: Science Attitudes } \\
\hline STEMSP & .012 & $(.022)$ & .015 & $(.031)$ & -.007 & $(.046)$ & .024 & $(.029)$ \\
\hline Female & -.026 & $(.022)$ & -.023 & $(.033)$ & -.027 & $(.022)$ & -.026 & $(.022)$ \\
\hline URM & -.040 & $(.027)$ & -.040 & $(.027)$ & -.056 & $(.039)$ & -.039 & $(.027)$ \\
\hline Low-SES & -.014 & $(.025)$ & -.013 & $(.025)$ & -.014 & $(.025)$ & .003 & $(.037)$ \\
\hline STEMSP $\times$ Female & & & -.005 & $(.043)$ & & & & \\
\hline STEMSP $x$ URM & & & & & .024 & $(.052)$ & & \\
\hline STEMSP $\times$ Low-SES & & & & & & & -.027 & $(.050)$ \\
\hline Intercept & .045 & $(.030)$ & .044 & $(.033)$ & .058 & $(.038)$ & .037 & $(.034)$ \\
\hline$R^{2}$ & \multicolumn{2}{|c|}{.006} & \multicolumn{2}{|c|}{.006} & \multicolumn{2}{|c|}{.006} & \multicolumn{2}{|c|}{.007} \\
\hline
\end{tabular}

Note. $\mathrm{N}=$ sample size; $\beta=$ coefficient $R S E=$ robust standard error; STEMSP = STEM summer program;

$\mathrm{URM}=$ underrepresented $\mathrm{racial} /$ ethnic minorities; $\mathrm{SES}=$ socioeconomic status.

$* * * p<.001 ; * * p<.01 ; * p<.05$ (two-tailed test).

\subsection{STEM summer program participation and interests in math- and science-related careers}

Our second set of regression analyses estimated the associations among STEM summer program participation and students' interests in math- and science-related careers. Table 4 reports results from estimating linear probability models that predict career interests in math and science with PREP participation, controlling for sociodemographic characteristics. Similar to the findings above, STEM summer program attendance is positively related to students' interest in math-related careers $(\beta=0.070, p<0.05)$ but has no effect on students' interest in science-related careers. There was also no evidence to suggest that the associations among STEM summer program participation and students' interests in math- and science-related careers differed by sociodemographic characteristics, including gender, race/ethnicity, and SES.

Table 4. Results of linear probability models $(\mathrm{N}=1.017)$

\begin{tabular}{|c|c|c|c|c|c|c|c|c|}
\hline & \multicolumn{2}{|c|}{ Model 1} & \multicolumn{2}{|c|}{ Model 2} & \multicolumn{2}{|c|}{ Model 3} & \multicolumn{2}{|c|}{ Model 4} \\
\hline & $\beta$ & $R S E$ & $\beta$ & $R S E$ & $\beta$ & $R S E$ & $\beta$ & $R S E$ \\
\hline \multicolumn{9}{|c|}{ Panel 1: Math Career Interest } \\
\hline STEMSP & $.070^{*}$ & $(.032)$ & .027 & $(.045)$ & .040 & $(.069)$ & .051 & $(.042)$ \\
\hline Female & $-.173 * * *$ & $(.030)$ & $-.223 * * *$ & $(.050)$ & $-.173 * * *$ & $(.030)$ & $-.174 * * *$ & $(.030)$ \\
\hline URM & .008 & $(.037)$ & .007 & $(.037)$ & -.017 & $(.063)$ & .006 & $(.038)$ \\
\hline Low-SES & -.002 & $(.036)$ & -.004 & $(.036)$ & -.003 & $(.036)$ & -.038 & $(.057)$ \\
\hline STEMSP $\times$ Female & & & .080 & $(.063)$ & & & & \\
\hline STEMSP $\times$ URM & & & & & .037 & $(.077)$ & & \\
\hline STEMSP $\times$ Low-SES & & & & & & & .058 & $(.072)$ \\
\hline Intercept & $.639 * * *$ & $(.046)$ & $.665 * * *$ & $(.050)$ & $.659 * * *$ & $(.061)$ & $.654 * * *$ & $(.051)$ \\
\hline$R^{2}$ & \multicolumn{2}{|c|}{.035} & \multicolumn{2}{|c|}{.036} & \multicolumn{2}{|c|}{.035} & \multicolumn{2}{|c|}{.035} \\
\hline \multicolumn{9}{|c|}{ Panel 2: Science Career Interest } \\
\hline STEMSP & -.005 & $(.031)$ & -.043 & $(.044)$ & -.040 & $(.064)$ & .028 & $(.040)$ \\
\hline Female & $-.051^{\dagger}$ & $(.030)$ & $-.094^{\dagger}$ & $(.059)$ & $-.051^{\dagger}$ & $(.030)$ & $-.050^{\dagger}$ & $(.030)$ \\
\hline URM & -.035 & $(.036)$ & -.036 & $(.036)$ & -.064 & $(.059)$ & -.034 & $(.035)$ \\
\hline Low-SES & -.040 & $(.034)$ & -.042 & $(.034)$ & -.041 & $(.034)$ & .004 & $(.054)$ \\
\hline STEMSP $\times$ Female & & & .070 & $(.061)$ & & & & \\
\hline STEMSP $\times$ URM & & & & & .044 & $(.073)$ & & \\
\hline STEMSP $x$ Low-SES & & & & & & & -.070 & $(.069)$ \\
\hline Intercept & $.764 * * *$ & $(.043)$ & $.786 * * *$ & $(.047)$ & $.787 * * *$ & $(.057)$ & $.739 * * *$ & $(.048)$ \\
\hline$R^{2}$ & \multicolumn{2}{|c|}{.008} & \multicolumn{2}{|c|}{.009} & \multicolumn{2}{|c|}{.008} & \multicolumn{2}{|c|}{.010} \\
\hline
\end{tabular}

Note. $\mathrm{N}=$ sample size; $\beta=$ coefficient; $R S E=$ robust standard error; STEMSP = STEM summer program;

$\mathrm{URM}=$ underrepresented racial/ethnic minorities; SES = socioeconomic status.

*** $p<.001 ; * * p<.01 ; * p<.05 ;{ }^{\dagger} p<.10$ (two-tailed test)

Int. J. Eval. \& Res. Educ. Vol. 8, No. 2, June 2019: 356 - 362 


\section{CONCLUSION}

To recap, the findings of this study indicate that participating in PREP-an OST STEM program-is positively associated with higher levels of students' attitudes toward math and interest in math-related careers, but has no significant relationships with students' science attitudes and career interests. These results were encouraging for OST STEM program providers and educators. However, it is important to note that estimates were not causal as there may be confounding factors that were not accounted for, which could bias our results. Nonetheless, by analyzing a large sample of middle school students from multiple cohorts and sociodemographically diverse backgrounds, this study offers new evidence suggesting that OST STEM programs could be a promising intervention to increase student motivational factors in STEM areas. Furthermore, our findings indicate that OST STEM programs have no differential effects for students across gender, racial/ethnic, or SES groups. Future initiatives aimed at improving STEM learning and participation among underrepresented groups, including women, URM, and low-SES students, could be designed to and test for gender-specific or culturally responsive interventions or programs in STEM.

\section{ACKNOWLEDGEMENTS}

This study was funded by an American Educational Research Association Research Grant (with support from the US National Science Foundation) and a research grant from the Grants for Research Advancement and Transformation program by the Office of the Vice President for Research, Economic Development and Knowledge Enterprise at the University of Texas at San Antonio (UTSA). The authors also thank Joseph Kulhanek and Krystal Peralez from the UTSA Institute for P-20 Initiatives for their support and constructive feedback on this study.

\section{REFERENCES}

[1] Marginson S., Tytler R., Freeman B., \& Roberts K., "STEM: Country comparisons: International comparisons of science, technology, engineering and mathematics (STEM) education, ". Final report, 2013.

[2] White House. "A strategy for American innovation: Securing our economic growth and prosperity, ". Washington, DC: Executive Office of the President, 2011.

[3] Means, B., Wang, H., Wei, X., Lynch, S., Peters, V., Young, V., \& Allen, C., "Expanding STEM opportunities through inclusive STEM-focused high schools," Science Education, vol. 101(5), pp. 681-715, 2017.

[4] Saw, G. K., "The impact of inclusive STEM high schools on student outcomes: A statewide longitudinal evaluation of Texas STEM academies," International Journal of Science and Mathematics Education, in press.

[5] Beymer, P. N., Rosenberg, J. M., Schmidt, J. A., \& Naftzger, N. J., "Examining relationships among choice, affect, and engagement in summer stem programs," Journal of Youth and Adolescence, vol. 47, pp. 1178-1191, 2018.

[6] Elam, M. E., Donham, B. L., \& Solomon, S. R., "An engineering summer program for underrepresented students from rural school districts," Journal of STEM Education: Innovations and Research, vol. 13(2), pp. 35-44, 2012.

[7] Knox, K., Moynihan, J., \& Markowitz, D., "Evaluation of short-term impact of a high school summer science program on students' perceived knowledge and skills," Journal of Science Education and Technology, vol. 12(4), ppp. 471478, 2003.

[8] Chen, C., Tomsovic, K., \& Aydeniz, M., "Filling the pipeline: Power system and energy curricula for middle and high school students through summer programs," IEEE Transactions on Power Systems, vol. 29(4), pp. 1874-1879, 2014.

[9] Goonatilake, R., \& Bachnak, R., "Promoting engineering education among high school and middle school students," Journal of STEM Education, vol. 13(1), pp. 15-21, 2012.

[10] Kitchen, J. A., Sonnert, G., \& Sadler, P., "The impact of college- and university-run high school summer programs on students' end of high school STEM career aspirations," Science Education, vol. 102(3), pp. 1-19, 2018.

[11] Markowitz, D., "Evaluation of the long-term impact of a university high school summer science program on students' interest and perceived abilities in science," Journal of Science Education and Technology, vol. 13(3), pp. 395-407, 2004

[12] Niemann, M. A., Miller, M. L., \& Davis, T., "The University of Alabama at Birmingham Center for Community Outreach Development Summer Science Institute program: A 3-yr laboratory research experience for inner-city secondary level students," Cell Biology Education, vol. 3, pp. 162-180, 2004.

[13] Timme, N., Baird, M., Bennett, J., Fry, J., Lance, G., \& Maltese, A., "A summer math and physics program for high school students: Student performance and lessons learned in the second year," The Physics Teacher, vol. 51, pp. 280284, 2013.

[14] Bachman, N., Bischoff, P., Gallagher, H., Labroo, S., \& Schaumloffel, J., "PR2EPS: Preparation, recruitment retention and excellence in the physical sciences, including engineering. A report on the 2004, 2005, and 2006, science summer camps," Journal of STEM Education, vol. 9(1-2), pp. 30-39, 2008.

[15] Kabacoff, C., Srivastava, V., \& Robinson, D., "A summer academic research experience for disadvantaged youth," CBE-Life Sciences Education, vol. 12, pp. 410-418, 2013. 
[16] Miller, K., Carrick, T., Martinez-Sussmann, C., Levine, R., Andronicos, C., \& Langford, R., "Effectiveness of a summer experience for inspiring interest in geoscience among Hispanic-American high school students," Journal of Geoscience Education, vol. 55(6), pp. 596-603, 2007.

[17] Salto, L. M., Riggs, M. L., De Leon, D. D., Casiano, C. A., \& De Leon, M., "Underrepresented minority high school and college students report STEM-pipeline sustaining gains after participating in the Loma Linda University summer health disparities research program," PLoS One, vol. 9(9), 2014.

[18] Nugent, G., Barker, B., Grandgenett, N., \& Adamchuk, V. I., "Impact of robotics and geospatial technology interventions on youth STEM learning and attitudes," Journal of Research on Technology in Education, vol. 42(4), pp. 391-408, 2010.

[19] Constan, Z., \& Spicer, J. J., "Maximizing Future Potential in Physics and STEM: Evaluating a Summer Program through a Partnership between Science Outreach and Education Research," Journal of Higher Education Outreach and Engagement, vol. 19(2), pp. 117-136, 2015.

[20] Nugent, G., Barker, B., Grandgenett, N., \& Adamchuk, V. I., "Impact of robotics and geospatial technology interventions on youth STEM learning and attitudes," Journal of Research on Technology in Education, vol. 42(4), pp. 391-408, 2010.

[21] Martinez, E., Lindline, J., Petronis, M. S., \& Pilotti, M., "Effectiveness of a science agricultural summer experience (SASE) in recruiting students to natural resources management," Journal of Science Education and Technology, vol. 21(6), pp. 713-721, 2012.

[22] Mohr-Schroeder, M. J., Jackson, C., Miller M., Walcott B., Little D. L., Speler L., Schooler W., Schroeder D. C., "Developing Middle School Students' Interests in STEM via Summer Learning Experiences: See Blue STEM Camp," School Science and Mathematics, vol. 114(6), pp. 291-301, 2014.

[23] Saw, G. K., Chang, C.-N., \& Chan, H.-Y., "Cross-sectional and longitudinal disparities in STEM career aspirations at the intersection of gender, race/ethnicity, and socioeconomic status," Educational Researcher, vol. 47(8), pp. 525-532, 2018.

[24] Saw, G. K., \& Chang, C.-N., "Cross-lagged models of mathematics achievement and motivational factors among Hispanic and non-Hispanic high school students," Hispanic Journal of Behavioral Sciences, vol. 40(2), pp. 240-256, 2018.

[25] Unfried, A., Faber, M., Stanhope, D. S., \& Wiebe, E., "The development and validation of a measure of student attitudes toward science, technology, engineering, and math (S-STEM)," Journal of Psychoeducational Assessment, vol. 33(7), pp. 622-639, 2015.

[26] Jackson, D. L., Gillaspy, J. A., \& Purc-Stephenson, R., "Reporting practices in confirmatory factor analysis: An overview and some recommendations," Psychological Methods, vol. 14(1), pp. 6-23, 2009.

[27] Hu, L.-t., \& Bentler, P. M., "Cutoff criteria for fit indexes in covariance structure analysis: Conventional criteria versus new alternatives," Structural Equation Modeling, vol. 6(1), pp. 1-55, 1999.

[28] Cronbach, L. J., "Coefficient alpha and the internal structure of tests," Psychometrika, vol. 16, 297-334, 1951.

[29] Wooldridge, J. M., "Introductory Econometrics: A Modern Approach (5th.)," Mason, OH: South-Western, 2012.

Int. J. Eval. \& Res. Educ. Vol. 8, No. 2, June 2019: 356 - 362 